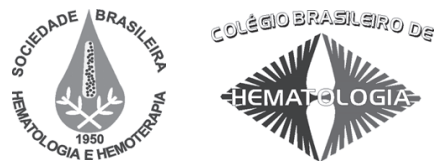

Review / Revisão

\title{
Allogeneic transplantation in multiple myeloma
}

\section{Transplante alogênico no mieloma múltiplo}

Ignazio Majolino

Alessandro Severino
In this review the authors present a state of art tretment of multiple myeloma. High dose chemo-radiotherapy followed by autologous hematopoietic stem cell transplantation has been show to be superior a conventional chemotherapy and a double transplantation. The authors discuss too, the allogeneic transplantation with reduced intensity conditioning, allogeneic versus tandem autologous, results the patients long term outcome and a approach about the use of donor lymphocytes, anti thimocyte globulin and a overview of post transplant therapies. Rev. Bras. Hematol. Hemoter. 2009;31(Supl. 2):35-40.

Key words: Multiple myeloma; high dose chemotherapy; autologous transplant; allogeneic transplant; treatment.

\section{Introduction}

In multiple myeloma (MM), high-dose chemoradiotherapy followed by autologous hematopoietic stem cell transplantation (HSCT) has been shown to be superior to conventional chemotherapy, ${ }^{1}$ and in some studies the results of double (so-called tandem) autologous transplantation were better than those of single transplants, at least in patients with an incomplete response to the first autograft. ${ }^{2,3}$ Autologous HSCT is now the gold standard in the treatment of MM patients with less than 60-65 years of age. Nevertheless, autologous HSCT patients will almost inevitably relapse. ${ }^{4}$ In fact, even in favorable conditions, a considerable relapse rate approaching $60 \%$ at 5 years is reported after autotransplants, and no plateau is yet apparent on relapse-free survival curves. A reason for the partial defeat of the autograft strategy is the failure of the conditioning regimen to eradicate the myeloma clone. Another possible explanation is tumor contamination of the graft. In principle, allogeneic HSCT would overcome both these problems, since in the allogeneic setting the graft sample is devoid of neoplastic cells and the graft-vs-myeloma $(\mathrm{GVM})^{5}$ effect could get rid of the minimal disease surviving the high-dose regimen.
In fact, allogeneic HSCT is the only therapeutic modality that offers long disease-free survival and possibly a cure to a fraction of patients. This however is achieved at the cost of considerable morbidity and mortality. ${ }^{6}$

In MM, survival strictly correlates with the quality of response, and the use of more sensitive techniques for minimal disease detection further reinforce the concept of response as a predictor of survival. In MM bone marrow samples, immunoglobulin $\mathrm{H}$ gene clonal rearrangement enables the construction of custom primers for individual patients who can be analysed by polymerase chain reaction (PCR). A negative PCR status is currently obtained in a substantial fraction of patients undergoing allogeneic $\mathrm{HSCT}^{7}$, but seldom after autologous transplantation. Using this sensitive technique, Corradini et al. ${ }^{8}$ analysed a series of 70 allogeneic MM patients, showing 100\% 5-year survival in those persistently PCR negative, $33 \%$ in those PCR-mixed and $0 \%$ in PCR-positive subjects. An effort should then be made to achieve the status of PCR-negative complete remission.

Patients with MM are usually elderly, and often in bad condition. They may present with renal failure, or develop it later in the course of disease. In part, as a consequence of the above mentioned factors, the clinical experience with

Hematology and Stem Cell Transplantation Unit, Institute of Hematotherapy,

Ospedale S. Camillo, Rome, Italy

Correspondence: Ignazio Majolino

UOC Ematologia e Trapianto di Cellule Staminali

Padiglione Morgagni, Ospedale S.Camillo

Circonvallazione Gianicolense 87, 00135 - Roma - Italy

Tel.: 0658703495 - Fax.: 065970435

E-mail:imajolino@scamilloforlanini.rm.it 
allogeneic HSCT in MM patients has been limited. A historical Seattle study of 80 patients, $71 \%$ refractory to therapy at the time of transplantation, reported an impressive transplantrelated mortality (TRM) of $44 \%$ within 100 days, and 57\% overall. The time from diagnosis to transplant date was the only statistical factor influencing TRM. A retrospective casematched analysis performed within the EBMT Registry ${ }^{6}$ compared the results of allogeneic with those of autologous HSCT in MM. In this study, 189 allogeneic MM patients were compared with an equal number of autologous patients. TRM was $13 \%$ in auto versus $41 \%$ in allo. The relapse/ progression rate was significantly higher in the autologous transplant patients $(70 \%$ as compared with $50 \%$ of the allogeneic group). Nonetheless, the median OS and progression-free survival (PFS) were 34 and 20 months in the autologous and 18 and 11 months in the allogeneic group, respectively. A similar comparison was performed at the Arkansas University. ${ }^{10}$ Only patients refractory to a previous autologous HSCT conducted with melphalan $\left(200 \mathrm{mg} / \mathrm{m}^{2}\right)$ were analyzed. In the allogeneic group 35 patients were allografted from HLA-identical siblings and 7 from HLAidentical unrelated donors. In 14 patients the graft was Tdepleted. Again TRM was much higher in the allogeneic group ( $43 \%$ vs. $10 \%$ ), while probability of disease progression was superior in the autologous ( $72 \%$ vs. $31 \%$ ). Interestingly, no progression was seen in the allogeneic patients 20 months after transplantation. Due to TRM, the 3 year probability of OS was higher for the autologous group ( $54 \%$ vs. $29 \%$ ), while the event-free survival (EFS) was comparable ( $25 \%$ vs. $20 \%$ ).

The main causes of death following allogeneic HSCT are severe infections, often combined with severe GVHD. However, in the last few years, changes in supportive modalities, such as new antibiotics and better GVHD prevention, have yielded a reduction of TRM with an overall improvement of the results. ${ }^{11}$ In autologous HSCT, the use of peripheral blood stem cells (PBSC) instead of bone marrow reduces the time of engraftment and transplant complications. In the allogeneic setting we lack clear evidence in favor of allogeneic PBSC. However, in the clinical practice G-CSFmobilized PBSC is increasingly used also for allogeneic HSCT. Although transplantation of PBSC is associated with faster engraftment and more frequent chronic GVHD, OS, nonrelapse mortality, relapse/progression and PFS are similar to those following BM transplants.

\section{Reduced-intensity conditioning}

If reduced-intensity conditioning (RIC) is used instead of myeloablative conditioning, either PBSC and BM transplants are associated with lower TRM. ${ }^{12}$ The Seattle group had a pivotal role in the development of this transplant modality, even in patients with MM. They used a lowintensity conditioning with 2 Gy TBI, and GVHD prevention with mycophenolate mofetil and cyclosporine. ${ }^{13}$ TRM was reduced consistently. Using this regimen, with the addition of fludarabine $\left(30 \mathrm{mg} / \mathrm{m}^{2} \times 3\right)$, they allografted 24 refractory or relapsed MM patients using unrelated donors. In 13 of them the allograft was preceded by an autologous transplant.14 The 3-year non-relapse mortality was $21 \%$, complete response was observed in $42 \%$ and partial response in $17 \%$. At 3 years, OS and PFS were $61 \%$ and $33 \%$, respectively. Patients receiving tandem autologous-unrelated allogeneic HSCT did better than those proceeding directly to unrelated donor HSCT (OS $77 \%$ vs. $44 \%$; PFS $51 \%$ vs. $11 \%$ ).

In a recent retrospective study (15), RIC was compared to myeloablative conditioning. RIC was associated with lower non-relapse mortality at 2 years ( $24 \%$ vs. $37 \%)$ but a higher relapse rate (54\% vs. $27 \%$ ) compared to myeloablative conditioning. The PFS was superior with myeloablative conditioning ( $34.5 \%$ vs. $18.9 \%$ ) but there was no significant difference in OS. The use of in-vivo T-cell depletion with ATG or alemtuzumab was associated with a higher risk of relapse-progression, and alemtuzumab in addition with poorer PFS and OS. The reduction in TRM was offset by an increase in relapse rate. However this was not a randomized study, the patients were in advanced stage (median time from diagnosis to allotransplantation 1.6 years) and those in the group with RIC were older.

Majolino et al. ${ }^{16}$ employed a conditioning regimen with intermediate doses of myeloma-active drugs. Fifty-three patients were allografted from their HLA identical siblings using thiotepa $(5 \mathrm{mg} / \mathrm{kg})$, fludarabine $\left(90 \mathrm{mg} / \mathrm{m}^{2}\right)$, and melphalan $\left(80 \mathrm{mg} / \mathrm{m}^{2}\right)$. Their median age was 52 years (range: 38-68) and the interval from diagnosis (median) 12 months. Forty-three patients $(82 \%)$ had advanced disease and 33 had previously been treated with high-dose therapy with one $(\mathrm{N}=21)$ or more $(\mathrm{N}=12)$ autologous transplants. Ten $(18 \%)$ had their allograft programmed after induction chemotherapy. The majority $(\mathrm{N}=44)$ received peripheral blood as stem cell source. Acute graft-versus-host disease (GVHD) grade II - IV developed in $45 \%$, but grade III - IV in only $5 \%$. Cumulative incidence of chronic GVHD was $64 \%$. Sixty-two percent were in complete remission (CR) following HSCT. TRM was $13 \%$ and relapse incidence was $32 \%$. With a median follow-up of 22 months, 3 -year overall survival was $45 \%$ and progression free survival $37 \%$. The authors concluded that the thiotepa, fludarabine, and melphalan conditioning regimen can produce remissions in the majority of MM patients with a limited TRM. When used as first line treatment the results of HSCT appear even more encouraging.

\section{Allogeneic versus tandem autologous}

Several groups have studied the impact of a tandem approach combining the reduction of tumor burden obtained by autologous HSCT with the GVM effect of RIC allotransplantation. In the literature there are three prospective studies based on the so-called genetic randomization, i.e. 
patients with an HLA-identical sibling are offered a RIC HSCT following the autologous, while other patients received either one or two autologous HSCT. In the IFM study, ${ }^{17}$ only highrisk de-novo MM patients ( $\mathrm{N}=280)$ were included. Following VAD induction they were assigned to tandem autologous HSCT or tandem autologous-allogeneic HSCT with a RIC of busulfan $(2 \mathrm{mg} / \mathrm{kg} \times 2)$, fludarabine $\left(25 \mathrm{mg} / \mathrm{m}^{2} \times 5\right)$ and antithymocyte globulin (ATG $-2.5 \mathrm{mg} / \mathrm{kg}$ x 5). Response rate was slightly superior in the allogeneic group (62\% in the allogeneic vs. $51 \%$ in the autologous arm). On an intent to treat basis, OS and EFS did not differ significantly in the two arms (median survival 35 months in the allogeneic vs. 41 months in the autologous; median EFS 25 months in the allogeneic vs. 30 months in the autologous). The use of ATG during the preparative regimen in the allogeneic group might be responsible for these results due to inhibition of the GVM effect. The results were not substantially different in the recently published update of this study. ${ }^{18}$

The Italian group ${ }^{19}$ reported a significant survival advantage in favor of allo-RIC, both for EFS and OS. In this study patients were included in the trial irrespective of the risk category. The conditioning regimen in the allogeneic arm was the Seattle combination of TBI 2 Gy on day 0 followed by infusion of donor PBSC and mycophenolate-cyclosporine prophylaxis. After a median follow-up of 45 months, the median OS and EFS were longer in the 80 patients with HLA-identical siblings than in the 82 patients without HLA-identical siblings ( 80 months vs. 54 months; $\mathrm{P}=0.01$; and 35 months vs. 29 months; $\mathrm{P}=0.02$, respectively). Disease-related mortality was significantly higher in the double-autologous-transplant group ( $43 \%$ vs. $7 \%$; $\mathrm{P}<0.001$ ). However, in this study the results of the tandem autologous HSCT were surprisingly poor in patients who completed the double autograft protocol. Median OS was 58 months in this subgroup, which is clearly inferior to the results of other reported series of double autograft. ${ }^{3,20}$

In the PETHEMA study ${ }^{21} 100$ patients failing to achieve at least near CR after an autologous HSCT were assigned to receive a second autograft or an allogeneic RIC-allo conditioned with fludarabine $\left(25 \mathrm{mg} / \mathrm{m}^{2} \times 5\right)$ and melphalan $\left(70 \mathrm{mg} / \mathrm{m}^{2} \times 2\right)$, depending on HLA-identical donor availability. After the second HSCT the CR was significantly higher in the allo-RIC group ( $40 \%$ vs. $11 \%$; $\mathrm{P}=0.001)$. In the allo-RIC group there was also a trend toward a longer PFS (31 months vs. not reached; $\mathrm{P}=0.08$ ) with the presence of a plateau suggesting a curative potential for allografting that may rely on the GVM effect, but as consequence of the higher TRM no statistical difference was found in EFS and OS.

\section{Long-term outcome}

Two recent studies report data on long-term outcomes of MM patients who received tandem auto/allo HSCT. The first is a US collaborative study ${ }^{22}$ with 102 patients. Treatment consisted of high-dose melphalan and autograft followed by
2 Gy TBI with or without fludarabine and allograft from HLA-identical siblings. Post-grafting immunosuppression was cyclosporine or tacrolimus and mycophenolate. Median follow-up was 6.3 years. Forty-two percent developed acute grade II-IV GVHD and 74\% extensive chronic GVHD. TRM was 18\%. Complete remission (CR) plus very good partial remission (VGPR) after allo were $76 \%$. OS was $64 \%$ and $\mathrm{PFS} 36 \%$ at 5 years. In multivariate analysis, $\beta$-2-microglobulin $>3.5 \mu \mathrm{g} / \mathrm{mL}$ at diagnosis and auto/allo procedure more than 10 months after treatment initiation correlated with short OS and PFS. A comparison with the study of double autologous HSCT by Attal et al. ${ }^{2}$ showed a superiority both for 5-year OS and for PFS ( $47 \%$ and $26 \%$, respectively). Cytogenetics was not regularly performed and showed no negative impact on transplantation results. GVHD was the main cause of TRM.

The second study was published in the same issue of Blood. It is a GITMO collaborative study ${ }^{23}$ It included 100 newly diagnosed patients, but 52 of them had already been described in an earlier report. ${ }^{19}$ After induction therapy with $\mathrm{VAD}$, the patients received a single autograft with melphalan $\left(200 \mathrm{mg} / \mathrm{m}^{2}\right)$ and an allograft with 2 Gy irradiation as conditioning. Post-grafting immunosuppression was cyclosporine + mycophenolate. Overall response was $91 \%$, CR+VGPR $69 \%$. Overall relapse rate was $41 \%$, but only $27 \%$ from CR or VGPR. Acute grade II-IV GVHD was $38 \%$ and chronic extensive GVHD was 50\%. Chronic GVHD was not associated with achievement of CR or disease relapse/ progression. Median OS was not reached and the median EFS was 2.9 years.

\section{Donor lymphocytes}

Strategies to improve the results of allogeneic HSCT include the use of donor-lymphocyte infusions (DLI) and the addition of new drugs in the transplant or posttransplant regimen. DLI are able to induce a response in $30 \%$ of the patients. In a collaborative study ${ }^{24}$, DLI were given for relapsed $(\mathrm{n}=48)$ or persistent $(\mathrm{n}=15) \mathrm{MM}$ following non-myeloablative allogeneic HSCT. Twenty-four of 63 patients (38.1\%) responded: 12 patients $(19.0 \%)$ with a partial response and 12 patients (19.0\%) with a complete response. Overall survival after DLI was 23.6 months. Median OS for non-responding patients was 23.6 months and has not been reached for the patients responding to DLI. In responders, PFS after DLI was 27.8 months. Patients with a PR had a median PFS of 7.0 months, whereas patients with a CR to DLI had a median PFS of 27.8 months. Major toxicities were acute GVHD (38.1\%) and chronic GVHD (42.9\%). Seven patients (11.1\%) died from treatment-related mortality. The only significant prognostic factors for response to DLI were the occurrence of acute and chronic GVHD. There was a trend towards significance for time between transplantation and DLI, and response. This study 
demonstrates that DLI are a valuable alternative following HSCT, but their effect cannot be separated from GVHD.

\section{Anti-thymocyte globulin}

Inclusion of ATG in allogeneic HSCT protocols for patients with MM may increase remission rates and at the same time prevent graft-versus-host disease. The role of ATG in the conditioning regimen has been investigated by Ayuk et al. ${ }^{25}$ in a collaborative study. The ATG was the human Jurkat T-cell-line derived anti-thymocyte globulin (Fresenius). It was administered in a melphalan/fludarabinebased RIC in 138 MM patients who underwent allogeneic HSCT with $(n=79)$ or without ( $\mathrm{n}=59)$ ATG. Inclusion of ATG led to a better 100 -day overall response rate (93\% vs. $78 \%$; $\mathrm{p}=0.03)$ and complete response rate $(59 \%$ vs. $39 \%$; $\mathrm{p}=0.04)$, to a lower incidence of both acute grade III/IV GVHD (11\% vs. $22 \%$; $p=0.10)$ and chronic GVHD ( $23 \%$ vs. $65 \%$; $p<0.001)$ and to a trend of improved EFS at three years (39\% vs. $27 \%$; $\mathrm{p}=0.5$ ). There was no difference in the estimated cumulative incidence of TRM at one year between the groups receiving or not ATG ( $25 \%$ vs. $26 \%)$. In multivariate analysis, treatment with ATG was the only significant factor for attaining complete remission (RR: $2.57 ; \mathrm{p}=0.02$ ). These results are in contrast to those of the EBMT study ${ }^{15}$ reporting a lower response and lower EFS among recipients of ATG. In the EBMT study, thymoglobulin, an anti-thymocyte globulin derived from human thymocytes, was the most commonly used preparation, and this may have less anti-myeloma but still a strong T-cell depletion effect in comparison with ATG Fresenius. However, it must be pointed out that among the studies described above, the best results were obtained by Bruno et al. ${ }^{19}$ who did not include any immunosuppression in the conditioning regimen, while the worst ones were obtained by Garban et al..$^{17}$ who used high doses of ATG.

\section{Post-transplantation therapies}

The clinical relevance of post-transplantation therapies to improve remission, and remission depth for long-term survival in myeloma patients was analyzed in a study by Kröger et al. ${ }^{26}$ Thirty-two patients with MM who achieved only partial remission after allogeneic HSCT were treated with DLI. If no CR was achieved, one of the novel agents was added to target CR. CR defined either by EBMT criteria, flow cytometry, or molecular methods as assessed by patientspecific immunoglobulin, H-PCR or plasma cell chimerism PCR was accomplished in $59 \%, 63 \%$, and $50 \%$ of patients, respectively. Attainment of CR resulted in improved 5-year PFS and OS, according to EBMT criteria (53\% vs. $35 \%$; $p=$ 0.03 and $90 \%$ vs. $62 \% ; p=0.06$, respectively), flow cytometry ( $74 \%$ vs. $15 \% ; p=0.001$ and $100 \%$ vs. $52 \%$; $p=0.1$, respectively), or molecular methods $(84 \%$ vs. $38 \% ; p=0.001$ and $100 \%$ vs. $71 \% ; \mathrm{p}=0.03$, respectively).
The novel agents, bortezomib, thalidomide and lenalidomide may have strong immunomodulating effects resulting in enhancement of graft-versus-tumor reactions without stimulation of GVHD. In a cohort of $18 \mathrm{MM}$ patients from 8 European institutions who did not respond or relapsed after DLI and received additional treatment with bortezomib and thalidomide, all the 7 patients treated with bortezomib responded with PR or VGPR, while 6 of 9 patients achieved a PR after treatment with thalidomide and 2 of 2 receiving both drugs achieved CR. ${ }^{27}$ In a retrospective evaluation ${ }^{28}$ of 23 patients with $\mathrm{MM}$ who had relapsed after allografting and received bortezomib as single agent (9 patients) or in combination with steroids (14 patients) the response rate was $61 \%$ including $22 \%$ immune-fixation negative CR. Median PFS was six months.

Bortezomib may be a safe and efficient option for myeloma patients after RIC allo-SCT. El-Cheikh et al. ${ }^{29}$ reported the results of bortezomib treatment following RIC allograft in $37 \mathrm{MM}$ patients. Thirty-two patients were in relapse, while five had residual disease. Twenty-seven patients obtained an objective response, 38\% CR or VGPR. Patients achieving an objective response survived longer. Bortezomib may be useful also in the management of cGVHD. Mateo-Mazon et al. ${ }^{30}$ report on the use of bortezomib for the management of cGVHD among eight MM patients who relapsed after RIC allogeneic HSCT. Five patients (62\%) responded to bortezomib demonstrating anti-myeloma effect. Four patients had active cGVHD, including three patients with severe punctate keratopathy at the time of bortezomib administration. All showed an improvement in their condition. In the recent report by Kröger et al. ${ }^{26}$ thirty-two patients with MM who achieved only partial remission after allogeneic HSCT were treated with DLI. Eleven of the 24 (45\%) failing this treatment entered a CR with one or two novel agents. Additionally, lenalidomide is a promising agent, and in the new GIMEMA study protocol of allogeneic transplantation for MM it has been included in the maintenance phase (Bruno B. Personal communication).

\section{Conclusion}

In conclusion, in MM, despite the improved results obtained with autologous transplantation and with the new therapeutic agents, cure is almost never obtained. The success of allogeneic HSCT however, is hampered by a high TRM. The use of RIC has led to a reduction in mortality but at the same time to an increase of relapse rate. Currently, allogeneic transplantation is not recommended except in clinical trials and in selected groups of patients. 


\section{Resumo}

Neste relato os autores apresentam uma revisão sobre o estado atual do tratamento mieloma múltiplo. São enfatizados aspectos sobre a vantagem do transplante autólogo em seguimento à quimioterapia convencional e o duplo transplante. São discutidos o transplante alogênico e o condicionamento com intensidade reduzida, além do uso de linfócitos do doador, da globulina antitimocítica e uma visão geral do futuro da terapia da moléstia. Rev. Bras. Hematol. Hemoter. 2009;31(Supl. 2):35-40.

Palavras-chave: Mieloma múltiplo; altas doses de quimioterapia; transplante autólogo; transplante alogênico.

\section{References}

1. Attal M, Harousseau JL, Stoppa AM, Sotto JJ, Fuzibet JG, Rossi JF, et al. A prospective, randomized trial of autologous bone marrow transplantation and chemotherapy in multiple myeloma. Intergroupe Français du Myélome. N Engl J Med. 1996;335(2):91-7.

2. Attal M, Harousseau JL, Facon T, Guilhot F, Doyen C, Fuzibet JG, et al. Single versus double autologous stem-cell transplantation for multiple myeloma. N Engl J Med. 2003;349(26):2495-502.

3. Cavo M, Tosi P, Zamagni E, Cellini C, Tacchetti P, Patriarca F, et al. Prospective, randomized study of single compared with double autologous stem-cell transplantation for multiple myeloma: Bologna 96 clinical study. J Clin Oncol. 2007;25(17):2434-41.

4. Majolino I, Vignetti M, Meloni G, Vegna ML, Scimè R, Tringali S, et al. Autologous transplantation in multiple myeloma: a GITMO retrospective analysis on 290 patients. Gruppo Italiano Trapianti di Midollo Osseo. Haematologica. 1999;84(9):844-52.

5. Tricot G, Vesole DH, Jagannath S, Hilton J, Munshi N, Barlogie B. Graft-versus-myeloma effect: proof of principle. Blood. 1996;87(3):1196-8.

6. Björkstrand BB, Ljungman P, Svensson H, Hermans J, Alegre A, Apperley $\mathrm{J}$, et al. Allogeneic bone marrow transplantation versus autologous stem cell transplantation in multiple myeloma: a retrospective case-matched study from the European Group for Blood and Marrow Transplantation. Blood. 1996;88(12): 4711-8.

7. Majolino I, Corradini P, Scimè R, Falda M, Bosi A, Tarella C, et al. High rate of remission and low rate of disease recurrence in patients with multiple myeloma allografted with PBSC from their HLA-identical sibling donors. Bone Marrow Transplant. 2003;31(9):767-73.

8. Corradini P, Cavo M, Lokhorst H, Martinelli G, Terragna C, Majolino I, et al. Molecular remission after myeloablative allogeneic stem cell transplantation predicts a better relapse-free survival in patients with multiple myeloma. Blood. 2003; 102(5):1927-9.

9. Bensinger WI, Buckner CD, Anasetti C, Clift R, Storb R, Barnett $\mathrm{T}$, et al. Allogeneic marrow transplantation for multiple myeloma: an analysis of risk factors on outcome. Blood. 1996; 88(7):2787-93.

10. Mehta J, Tricot G, Jagannath S, Ayers D, Singhal S, Siegel D, et al. Salvage autologous or allogeneic transplantation for multiple myeloma refractory to or relapsing after a first-line autograft? Bone Marrow Transplant. 1998;21(9):887-92.

11. Gahrton G, Svensson H, Cavo M, Apperly J, Bacigalupo A, Björkstrand $\mathrm{B}$, et al. Progress in allogenic bone marrow and peripheral blood stem cell transplantation for multiple myeloma: a comparison between transplants performed 1983--93 and 1994-8 at European Group for Blood and Marrow Transplantation centres. Br J Haematol. 2001;113(1):209-16.

12. Gahrton G, Iacobelli S, Bandini G, Björkstrand B, Corradini P, Crawley $\mathrm{C}$, et al. Peripheral blood or bone marrow cells in reducedintensity or myeloablative conditioning allogeneic HLA identical sibling donor transplantation for multiple myeloma. Haematologica. 2007;92(11):1513-8.

13. Maloney DG, Molina AJ, Sahebi F, Stockerl-Goldstein KE, Sandmaier BM, Bensinger W, et al. Allografting with nonmyeloablative conditioning following cytoreductive autografts for the treatment of patients with multiple myeloma. Blood. 2003;102(9):3447-54.

14. Georges GE, Maris MB, Maloney DG, Sandmaier BM, Sorror ML, Shizuru JA, et al. Nonmyeloablative unrelated donor hematopoietic cell transplantation to treat patients with poor-risk, relapsed, or refractory multiple myeloma. Biol Blood Marrow Transplant. 2007;13(4):423-32

15. Crawley C, Iacobelli S, Björkstrand B, Apperley JF, Niederwieser D, Gahrton G. Reduced-intensity conditioning for myeloma: lower nonrelapse mortality but higher relapse rates compared with myeloablative conditioning. Blood. 2007;109(8):3588-94.

16. Majolino I, Davoli M, Carnevalli E, Locasciulli A, Di Bartolomeo $\mathrm{P}$, Scimè $\mathrm{R}$, et al. Reduced intensity conditioning with thiotepa, fludarabine, and melphalan is effective in advanced multiple myeloma. Leuk Lymphoma. 2007;48(4):759-66.

17. Garban F, Attal M, Michallet M, Hulin C, Bourhis JH, YakoubAgha I, et al. Prospective comparison of autologous stem cell transplantation followed by dose-reduced allograft (IFM99-03 trial) with tandem autologous stem cell transplantation (IFM9904 trial) in high-risk de novo multiple myeloma. Blood. 2006; 107(9):3474-80.

18. Moreau P, Garban F, Attal M, Michallet M, Marit G, Hulin C, et al. Long-term follow-up results of IFM99-03 and IFM99-04 trials comparing nonmyeloablative allotransplantation with autologous transplantation in high-risk de novo multiple myeloma. Blood. 2008;112(9):3914-5.

19. Bruno B, Rotta M, Patriarca F, Mordini N, Allione B, CarnevaleSchianca $\mathrm{F}$, et al. A comparison of allografting with autografting for newly diagnosed myeloma. N Engl J Med. 2007;356 (11): $1110-20$.

20. Barlogie B, Tricot G, Anaissie E, Shaughnessy J, Rasmussen E, van Rhee F, et al. Thalidomide and hematopoietic-cell transplantation for multiple myeloma. N Engl J Med. 2006;354(10):1021-30.

21. Rosiñol L, Pérez-Simón JA, Sureda A, de la Rubia J, de Arriba F, Lahuerta JJ, et al. A prospective PETHEMA study of tandem autologous transplantation versus autograft followed by reducedintensity conditioning allogeneic transplantation in newly diagnosed multiple myeloma. Blood. 2008;112(9):3591-3.

22. Rotta M, Storer BE, Sahebi F, Shizuru JA, Bruno B, Lange T, et al Long-term outcome of patients with multiple myeloma after autologous hematopoietic cell transplantation and nonmyeloablative allografting. Blood. 2009;113(14):3383-91.

23. Bruno B, Rotta M, Patriarca F, Mattei D, Allione B, CarnevaleSchianca F, et al. Nonmyeloablative allografting for newly diagnosed multiple myeloma: the experience of the Gruppo Italiano Trapianti di Midollo. Blood. 2009;113(14):3375-82.

24. van de Donk NW, Kröger N, Hegenbart U, Corradini P, San Miguel JF, Goldschmidt H, et al. Prognostic factors for donor lymphocyte infusions following non-myeloablative allogeneic stem cell transplantation in multiple myeloma. Bone Marrow Transplant. 2006;37(12):1135-41. 
25. Ayuk F, Perez-Simon JA, Shimoni A, Sureda A, Zabelina T, Schwerdtfeger R, et al. Clinical impact of human Jurkat T-cellline-derived antithymocyte globulin in multiple myeloma patients undergoing allogeneic stem cell transplantation. Haematologica. 2008;93(9):1343-50

26. Kröger N, Badbaran A, Lioznov M, Schwarz S, Zeschke S, Hildebrand $\mathrm{Y}$, et al. Post-transplant immunotherapy with donor-lymphocyte infusion and novel agents to upgrade partial into complete and molecular remission in allografted patients with multiple myeloma. Exp Hematol. 2009;37(7):791-8.

27. van de Donk NW, Kröger N, Hegenbart U, Corradini P, San Miguel JF, Goldschmidt H, et al. Remarkable activity of novel agents bortezomib and thalidomide in patients not responding to donor lymphocyte infusions following nonmyeloablative allogeneic stem cell transplantation in multiple myeloma. Blood. 2006; 107 (8):3415-6.

28. Bruno B, Patriarca F, Sorasio R, Mattei D, Montefusco V, Peccatori J, et al. Bortezomib with or without dexamethasone in relapsed multiple myeloma following allogeneic hematopoietic cell transplantation. Haematologica. 2006;91(6):837-9.

29. El-Cheikh J, Michallet M, Nagler A, de Lavallade H, Nicolini FE, Shimoni A, et al. High response rate and improved graft-versushost disease following bortezomib as salvage therapy after reduced intensity conditioning allogeneic stem cell transplantation for multiple myeloma. Haematologica. 2008;93(3):455-8.

30. Mateos-Mazon J, Pérez-Simón JA, Lopez O, Hernández E, Etxebarria J, San Miguel JF. Use of bortezomib in the management of chronic graft-versus-host disease among multiple myeloma patients relapsing after allogeneic transplantation. Haematologica. 2007;92(9):1295-6.

O tema apresentado foi proposto pela Organização do $8^{\circ}$ Simpósio da Associação Ítalo-Brasileira de Hematologia, realizado durante o

XIII Congresso de Transplante de Medula Óssea.

Publicado após concordância do editor.

Conflito de interesse: sem conflito de interesse

Recebido: 26/06/2009

Aceito: 05/07/2009 